\title{
BMJ Open Is there evidence that the yearly numbers of children newly certified with sight impairment in England and Wales has increased between 1999/2000 and 2014/2015? A cross-sectional study
}

Catey Bunce, ${ }^{1}$ Antra Zekite, ${ }^{2}$ Richard Wormald, ${ }^{2}$ Richard Bowman ${ }^{3}$

To cite: Bunce C, Zekite A, Wormald $\mathrm{R}$, et al. Is there evidence that the yearly numbers of children newly certified with sight impairment in England and Wales has increased between 1999/2000 and 2014/2015? A crosssectional study. BMJ Open 2017;7:e016888. doi:10.1136/ bmjopen-2017-016888

- Prepublication history and additional material for this paper are available online. To view these files please visit the journal online (http://dx.doi. org/10.1136/bmjopen-2017016888).

Received 17 March 2017 Revised 15 May 2017

Accepted 13 June 2017

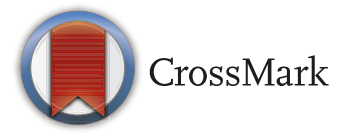

${ }^{1}$ Department of Primary Care \& Public Health Sciences, King's College London, London, UK ${ }^{2}$ Department of Research \& Development, Moorfields Eye Hospital NHS Foundation Trust, London, UK

${ }^{3}$ London School of Hygiene \& Tropical Medicine, London, UK

Correspondence to

Ms Catey Bunce;

catey.bunce@kcl.ac.uk

\section{ABSTRACT}

Objectives To use routine data capture from hospitals in England and Wales to identify whether there has been an increase in the annual numbers of children newly certified sight impaired in England and Wales between 1999/2000 and 2014/2015 and to examine causes of certifiable sight impairment in children certified in 2014/2015.

Design A cross-sectional study including an analysis of all certificates of vision impairment completed in hospitals in England and Wales each year between 2007/2008 and $2014 / 2015$ and all certificates completed in hospitals in England and Wales in 1999/2000.

Participants Certificates for all individuals aged 16 years or less at the time of certification in England and Wales for each financial year between 1 April 2007 and the 31 March 2015 and for individuals aged 15 years or less for the year ending 31 March 2000. We obtained information on the main cause of certifiable sight loss for all children certified in 2014/2015. We estimated crude and sex specific incidence estimates with 95\% confidence intervals computed by Byars method.

Results In 1999/2000, the estimated incidence (95\% $\mathrm{Cl}$ ) of certification was 8.2 (7.7 to 8.8) per 100000 . In $2007 / 2008$, the estimated incidence was statistically significantly higher at 10.1 (9.5 to 10.7). Since then a trend of increasing incidence with time has been observed until 2014/2015 when an estimated incidence of 13.3 (12.6 to 14.0) was observed. Hereditary retinal dystrophies, cerebral visual impairment and nystagmus were the most common single causes of certifiable sight impairment in children in 2014/2015.

Conclusion Our findings show that in England and Wales there has been an increase in the number of children newly certified sight impaired by consultant ophthalmologists since 1999/2000. This mirrors our previous findings based on data originating within social service departments.

\section{INTRODUCTION}

Prevention of sight impairment in children is an international priority. ${ }^{1}$ A study conducted during 2000 estimated that nearly six children per 10000 children born in the UK will
Strengths and limitations of this study

- Strengths include nationwide coverage, collection of uniform data fields with prespecified tick boxes and consistent definitions of sight impairment.

- Limitations include comparisons across two slightly different data collection forms and an interruption in data collection between 2000 and 2007

be severely sight impaired by their sixteenth birthday. ${ }^{2}$ Many countries lack contemporary data about the incidence of sight impairment but the UK has a routine data collection system providing information on sight impairment which dates back to $1851 .^{3}$ In the UK, when an individual's vision falls or is below a certain level, they may be offered registration as severely sight impaired (SSI: blind) or sight impaired (SI: partial sight). Registration for blindness or partial sight is the mechanism by which social service support for vision impairment is initiated but it also allows figures on the numbers newly sight impaired by cause to be collated. The system has evolved over time but since 2003, in England, Wales and Northern Ireland registration has been initiated by completion of a Certificate of Vision Impairment (CVI) by a consultant ophthalmologist. When a CVI is completed, one copy is sent to the child's social service department where it triggers a needs assessment and if consent is provided by the patient or carer, they are formally placed on a register with their local social service department. Registration may bring financial and practical benefits to the patients and there is evidence that in children early interventions can decrease risks of delayed development in motor, cognitive, language and social domains. ${ }^{4}$ In England and Wales, a copy of the CVI is sent to the Certifications Office for 
epidemiological analysis. The Certifications Office, based at Moorfields Eye Hospital, London operates under the auspices of the Royal College of Ophthalmologists and provides data to Public Health England and the Welsh Government.

In 2013, we reported on an increase in registrations for sight impairment in children in England. ${ }^{5}$ This analysis was based on information reported by the Health and Social Care Information Centre, based on triennial returns provided by councils with social service responsibilities. People with a CVI choose whether to be included in their local authority's register which means that not every child for whom a CVI is completed is recorded on a local authority register. ${ }^{6}$ Data relating to new registrations is captured in England but not in Wales, so our previous analysis was for England alone.

An alternative way of investigating temporal change over time in childhood vision impairment is to examine certification rates rather than registration rates. This allows examination of both Welsh and English data and is based on the medical certificate completed by the consultant ophthalmologist. This study was conducted to explore whether there has been an increase in the number of certifications for sight impairment in children over time and to ascertain the most common causes of certifiable sight impairment in children in 2014/2015.

\section{METHODS}

Approximately 24,000 CVIs arrive at the Certifications Office yearly. Patients provide written consent to certification and to their data being sent to the Certifications Office for epidemiological analysis. No additional consent was therefore sought. Data are transcribed from the paper certificates by trained data coders and entered into a database using a computer system which was developed during a Guide Dogs funded research project. A research assistant performs weekly validity checks and double data entry is conducted on a random sample of the data to ensure coding and consistency. Data captured include age at certification, gender, location, cause of certifiable visual loss and visual status - whether the patient is classified as severely sight impaired (SSI, blind) or sight impaired (SI, partially sighted). It is not easy to define certifiable visual loss in children. Children's vision develops over time and in very young babies, an accurate measure of visual acuity is not possible. ${ }^{7}$ Guidance (online appendix 1) is provided to assist the ophthalmologist which specify consideration of factors which contribute to visual function such as the best corrected visual acuity and visual field of the better-seeing eye. It should be noted, however, that this guidance allows the certifying ophthalmologist to make an holistic decision as to whether that child should be certified as severely sight impaired or sight impaired. Part C of the CVI form collects information on the cause of visual loss. It contains a picking list of common diagnoses (mostly adult), a text field for conditions not covered within the list and instructs the person completing the form to select main cause using an asterisk or circle. An optional paediatric diagnostic form on children is available from the Royal College of Ophthalmologists.

The Certifications Office provided figures on the numbers of children newly certified for each financial year by age, sex and devolved nation between 2007/2008 and 2014/2015. Prior to introduction of the CVI, the certificate which initiated registration was known as the BD8. While BD8 data were not routinely sent to the Certifications Office, a grant was secured in 2003 which allowed BD8s completed during the year ending 31 March 2000 to be transferred from the Office of National Statistics to the Certifications Office for data entry and analysis. ${ }^{8}$ These data were captured in a similar fashion to data captured after 2007 with double data entry conducted on $5 \%$ of the data to ensure data validity. ${ }^{8}$ No certification data were transferred from paper certificates to electronic format between 2000 and 2007 which covered the transition period from the BD8 to the CVI. CVI but not BD8 data allowed for analysis by devolved nation. Causal data were provided by the Certifications Office for all children certified in the year ending 31 March 2015.

The incidence of certification was computed using as denominator age and sex specific mid-year population estimates from censuses since 2000 derived from the UK Office for National Statistics. Confidence intervals were computed using Byars method using Excel. ${ }^{9}$ Byar's method gives very accurate approximate confidence intervals for counts based on the assumption of a Poisson distribution. ${ }^{9}$

\section{RESULTS}

Table 1 presents crude estimates with $95 \%$ confidence intervals of the incidence of certification in children for England and Wales combined, stratified by certification status (SSI, SI or both including not specified). figure 1 presents these data graphically. table 2 presents sex specific estimates of the incidence of certification in children with $95 \%$ confidence intervals data for England and Wales combined. table 3 presents combined CVI figures for England and Wales. The median (IQ) age at certification was computed for each year. table 4 presents the main cause of certifiable visual loss by visual status (SSI or SI) for children certified during the year ending 31 March 2015. The number of children is shown as is the proportion of SSI or SI certifications. figure $2 \mathrm{a}$ and $\mathrm{b}$ present these data graphically.

Table 1 shows that number of certificates has increased over time. Lower figures are seen for 1999/2000 than in $2007 / 20008$ but it is important to note that the figures for 1999/2000 are for children aged 15 or less. It is clear however that the numbers newly certified in $2007 / 2008$ are statistically significantly lower than those for $2015 / 2015$ as evidenced by non-overlap of confidence intervals. This is seen for certificates overall and for SSI and SI. Table 2 shows that in each year, certification rates 
Table 1 Numbers of new certifications and crude estimates of the incidence of certification with $95 \%$ confidence intervals per 100000 children in England and Wales

\begin{tabular}{|c|c|c|c|c|c|c|c|c|c|}
\hline \multirow[b]{2}{*}{ Year ending } & \multicolumn{3}{|c|}{ SSI } & \multicolumn{3}{|c|}{ SI } & \multicolumn{3}{|c|}{ Total $^{*}$} \\
\hline & $\mathbf{N}$ & CR & $95 \% \mathrm{Cl}$ & $\mathbf{N}$ & CR & $95 \% \mathrm{Cl}$ & $\mathbf{N}$ & CR & $95 \% \mathrm{Cl}$ \\
\hline $2000 \dagger$ & 328 & 3.1 & (2.7 to 3.4 ) & 520 & 4.9 & (4.5 to 5.3 ) & 876 & 8.2 & (7.7 to 8.8 ) \\
\hline 2008 & 439 & 4.0 & (3.6 to 4.3 ) & 616 & 5.6 & (5.1 to 6.0 ) & 1117 & 10.1 & (9.5 to 10.7 ) \\
\hline 2009 & 471 & 4.2 & (3.9 to 4.6 ) & 635 & 5.7 & (5.3 to 6.2 ) & 1134 & 10.2 & (9.6 to 10.8 ) \\
\hline 2010 & 461 & 4.1 & (3.8 to 4.5 ) & 580 & 5.2 & (4.8 to 5.6 ) & 1077 & 9.7 & (9.1 to 10.3 ) \\
\hline 2011 & 537 & 4.8 & (4.4 to 5.2 ) & 615 & 5.5 & (5.1 to 5.9 ) & 1185 & 10.6 & (10.0 to 11.2 ) \\
\hline 2012 & 604 & 5.4 & (4.9 to 5.8 ) & 666 & 5.9 & (5.5 to 6.4 ) & 1294 & 11.5 & (10.9 to 12.1 ) \\
\hline 2013 & 536 & 4.7 & (4.3 to 5.1 ) & 731 & 6.4 & (6.0 to 6.9 ) & 1300 & 11.4 & (10.8 to 12.1 ) \\
\hline 2014 & 637 & 5.6 & (5.1 to 6.0 ) & 845 & 7.4 & (6.9 to 7.9 ) & 1501 & 13.1 & (12.5 to 13.8 ) \\
\hline 2015 & 614 & 5.3 & (4.9 to 5.8 ) & 890 & 7.7 & (7.2 to 8.2 ) & 1530 & 13.3 & (12.6 to 14.0 ) \\
\hline
\end{tabular}

${ }^{\star}$ Total: including visual status (SI or SSI) not specified †2000: age 15 and under

were slightly (although not statistically significantly in most years) higher for boys than girls. Increases are seen in both genders. When data are examined by devolved nation (table 3), a different pattern in observed in Wales than in England but numbers for Wales are much lower than for England and all estimates for Wales lie within the 95\% confidence intervals for England. The median age at certification was 5 years for each year assessed and so there was no evidence that the age at certification has changed over time. table 4 presents the common single causes of certifiable sight loss for children certified in $2014 / 15$. In $15 \%$ of cases the consultant ophthalmologist was unable to determine a single main cause. Hereditary retinal dystrophies were the most common single cause of both SSI and SI. Disorders of the visual cortex and brain was the next most common single cause in SSI, while nystagmus and other irregular eye movements were the second most common single cause of SI. The third most common single cause was disorders of the visual cortex and brain and albinism for SSI and SI. 29 children were certified visually impaired due to retinopathy of prematurity in

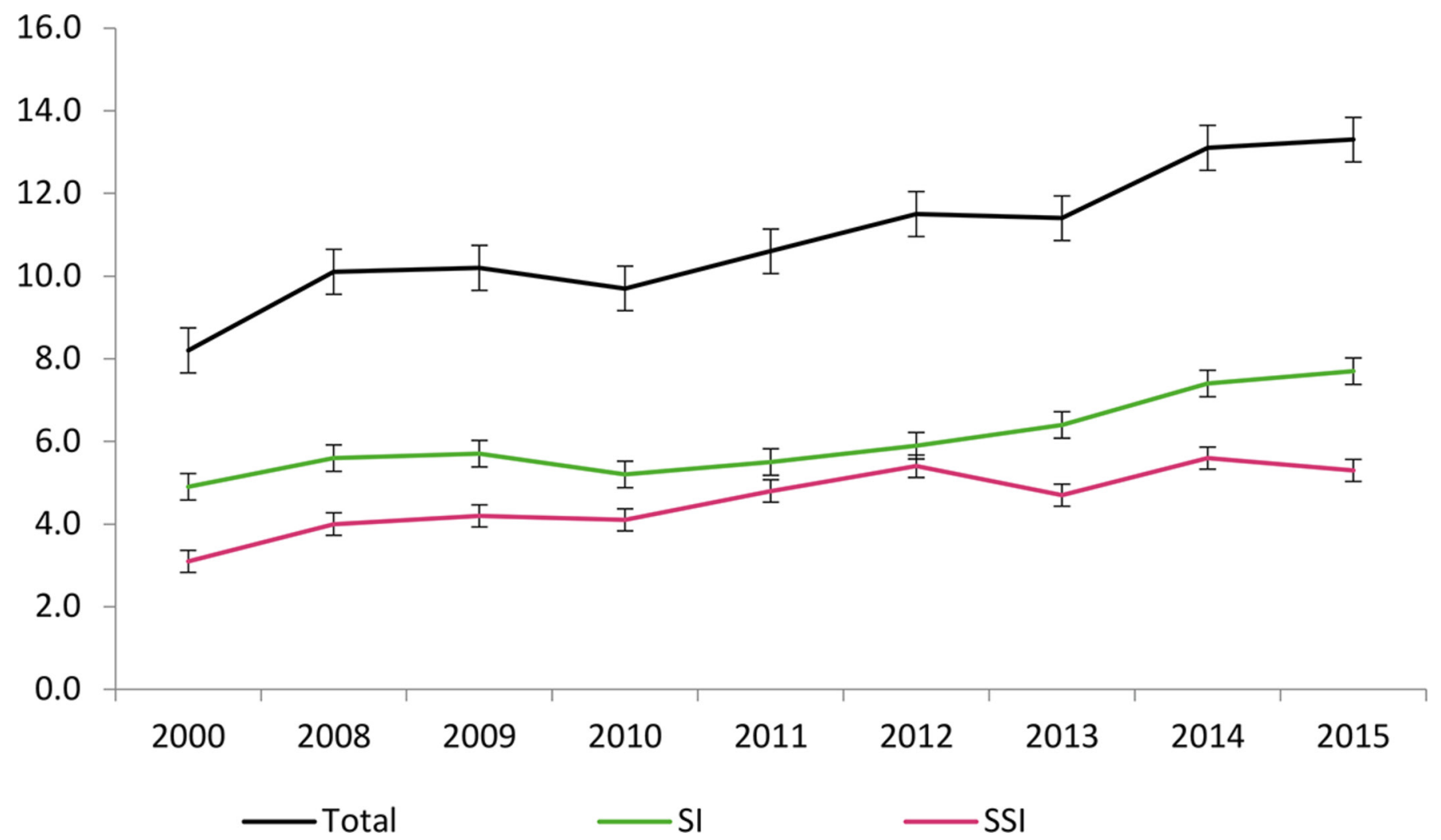

Figure 1 New certifications of severe sight impairment (SSI) and sight Impairment (SI) and total, crude rates per 100000 children in England and Wales and 95\% confidence intervals. 
Table 2 Numbers of new certifications and sex-specific estimates of incidence rate per 100000 children in England and Wales

\begin{tabular}{|c|c|c|c|c|c|c|}
\hline \multirow[b]{2}{*}{ Year ending } & \multicolumn{3}{|c|}{ Boys } & \multicolumn{3}{|c|}{ Girls } \\
\hline & $\mathbf{N}$ & Incidence & $95 \% \mathrm{Cl}$ & $\mathbf{N}$ & Incidence & $95 \% \mathrm{Cl}$ \\
\hline $2000^{*}$ & 472 & 8.6 & (7.8 to 9.4 ) & 371 & 7.1 & (6.4 to 7.9 ) \\
\hline 2008 & 611 & 10.8 & (9.9 to 11.6$)$ & 502 & 9.3 & (8.5 to 10.1 ) \\
\hline 2009 & 603 & 10.6 & (9.8 to 11.5$)$ & 525 & 9.7 & (8.9 to 10.5 ) \\
\hline 2010 & 582 & 10.2 & (9.4 to 11.1 ) & 494 & 9.1 & (8.3 to 9.9 ) \\
\hline 2011 & 654 & 11.4 & (10.5 to 12.3 ) & 529 & 9.7 & (8.9 to 10.5 ) \\
\hline 2012 & 692 & 12.0 & (11.1 to 12.9 ) & 601 & 10.9 & (10.1 to 11.8 ) \\
\hline 2013 & 718 & 12.3 & (11.4 to 13.3 ) & 576 & 10.4 & (9.6 to 11.3 ) \\
\hline 2014 & 784 & 13.4 & (12.4 to 14.3 ) & 715 & 12.8 & (11.9 to 13.8 ) \\
\hline 2015 & 859 & 14.5 & (13.6 to 15.6$)$ & 669 & 11.9 & (11.0 to 12.8$)$ \\
\hline
\end{tabular}

*Year ending 2000: age 15 and under

2014/15 compared with just 9 children in 2009/10 but 18 in $2008 / 9$.

\section{DISCUSSION}

The main objective of this study was to ascertain whether there had been an increase in the number of children being newly certified over time in England and Wales and to report on common causes of certifiable sight impairment in children.

These data provide strong evidence that there has been an increase in certifiable sight impairment in children in England and Wales over time. Statistically significantly more children were certified sight impaired in England and Wales in 2014/2015 than were certified sight impaired in England and Wales in 1999/2000 and in $2007 / 2008$. We previously reported on a trend observed with registration data in children in England only. ${ }^{5}$ The previous analysis was conducted using data arising from social service departments. The analysis presented here has used certification data which arises within hospitals rather than social services, examines causes of certifiable sight loss and includes Wales in addition to England
It is important to acknowledge that certification rates are likely to under-estimate true blindness rates. Certification is voluntary and there is no statutory requirement for it to be offered although the Royal College of Ophthalmologists consider it good practise to offer certification to all patients who are eligible. Vision typically improves with age and, when diagnosis and/or prognosis is uncertain, some ophthalmologists may wait months or in some cases years before offering certification. Determining certification status in children with developmental delay presents additional challenges which may impact on time to certification in children. ${ }^{4}$ Certification takes place within Eye clinics and there is evidence of poor uptake of hospital eye care for children with significant visual needs. ${ }^{10}$

For 12 months from January 2000, active surveillance was undertaken simultaneously but independently by the British Ophthalmological and the British Paediatric Surveillance units to identify children younger than 16 years diagnosed with severe visual impairment or blindness (SVI/BL, WHO criteria). ${ }^{2} 439$ children were identified in the surveillance study compared with 328

Table 3 Number of new certifications and country specific estimates of incidence rate per 100000 children in England and Wales

\begin{tabular}{|c|c|c|c|c|c|c|}
\hline \multirow[b]{2}{*}{ Year ending } & \multicolumn{3}{|c|}{ Wales } & \multicolumn{3}{|c|}{ England } \\
\hline & $\mathbf{N}$ & Incidence & $95 \% \mathrm{Cl}$ & $\mathbf{N}$ & Incidence & $95 \% \mathrm{Cl}$ \\
\hline 2008 & 58 & 9.6 & (7.3 to 12.5$)$ & 1059 & 10.1 & (9.5 to 10.7 ) \\
\hline 2010 & 74 & 12.4 & (9.7 to 15.6$)$ & 1003 & 9.5 & (8.9 to 10.1 ) \\
\hline 2011 & 75 & 12.6 & (9.9 to 15.8 ) & 1110 & 10.5 & (9.8 to 11.1 ) \\
\hline 2013 & 53 & 8.9 & (6.7 to 11.7 ) & 1247 & 11.6 & (10.9 to 12.2$)$ \\
\hline 2014 & 61 & 10.3 & (7.9 to 13.2 ) & 1440 & 13.3 & (12.6 to 14.0$)$ \\
\hline 2015 & 62 & 10.5 & (8.0 to 13.4 ) & 1468 & 13.4 & (12.7 to 14.1$)$ \\
\hline
\end{tabular}




\begin{tabular}{|c|c|c|c|c|c|c|c|}
\hline \multirow[t]{2}{*}{ ICD-9 } & \multirow[t]{2}{*}{ Description } & \multicolumn{2}{|c|}{ SSI } & \multicolumn{2}{|c|}{ SI } & \multicolumn{2}{|c|}{ Total } \\
\hline & & $\mathrm{n}$ & $\%$ & $\mathrm{n}$ & $\%$ & $\mathrm{n}$ & $\%$ \\
\hline 191 & All malignant neoplasms (excl eye) & 13 & 2 & 8 & 1 & 21 & 1 \\
\hline \multirow[t]{2}{*}{270.2} & Albinism & 22 & 4 & 88 & 10 & 113 & 7 \\
\hline & Retinopathy of Prematurity & 17 & 3 & 12 & 1 & 29 & 2 \\
\hline 362.7 & Hereditary retinal dystrophies (eg, Ushers) & 96 & 16 & 135 & 15 & 231 & 15 \\
\hline 377 (ex 377.7/.75) & Disorders of optic nerve and visual pathways & 70 & 11 & 69 & 8 & 140 & 9 \\
\hline $377.7,377.75$ & Disorders of visual cortex and brain & 90 & 15 & 91 & 10 & 188 & 12 \\
\hline 379.5 & Nystagmus and other irregular eye movements & 10 & 2 & 95 & 11 & 105 & 7 \\
\hline 742 & Congenital anomalies of brain \& nervous system & 34 & 5 & 28 & 3 & 63 & 4 \\
\hline 743 & Congenital anomalies of eye & 67 & 11 & 83 & 9 & 157 & 10 \\
\hline \multirow[t]{4}{*}{760} & Other congenital anomalies & 19 & 3 & 26 & 3 & 46 & 3 \\
\hline & No information on main cause/ illegible / invalid & 18 & 3 & 22 & 2 & 41 & 3 \\
\hline & Multiple Cause & 89 & 14 & 140 & 16 & 231 & 15 \\
\hline & Other causes & 69 & 11 & 93 & 11 & 165 & 11 \\
\hline Total & & 614 & & 890 & & 1530 & \\
\hline
\end{tabular}

children in this study. This lends support to the suggestion of CVI figures underestimating true blindness figure but is tempered by the fact that our study did not cover Northern Ireland or Scotland and by differing definitions of sight impairment.

Rises in certification numbers may not indicate rises in actual blindness since it is possible that there might have been an increase in certification coverage over time (ie, more of those who are eligible for certification are offered and accept it). There is some suggestion from table 1 that better ascertainment might explain some of the increase in that figures for 2014 are considerably higher than the previous year. It seems unlikely, however, that better ascertainment alone explains our observations and improvements in the processes were not commented on in a recent study conducted by the Royal National Institute of Blind People (RNIB) in children. ${ }^{4}$

In contrast there are plausible reasons for an increase in the incidence of blindness in children. This analysis shows that the leading cause of certifiable sight impairment in children in England and Wales during 2014/16 was 'hereditary retinal dystrophies' which includes conditions such as Retinitis Pigmentosa and Stargardt's disease. Retinal dystrophies were found to be a common cause of childhood certification in England and Wales when previous data were examined. ${ }^{11}$ Childhood retinal dystrophies have been found to be more common in children of Asian compared with White ethnicity. ${ }^{12}$ One possible explanation for this is consanguinity which may be more common among some ethnic minority groups. ${ }^{13}$ This might also account for the high prevalence of congenital anomalies. An increase in ethnic diversity has been observed in England and with the proportion of the population describing their ethnicity as white decreasing over time. ${ }^{14}$ The notion that consanguinity is associated with higher rates of visual impairment in children has been commented on previously when higher rates of registration were observed in Bradford than in the rest of England..$^{15} \mathrm{~A}$ study looking at Danish children has shown an increase in the prevalence of generalised retinal dystrophy between 1988 and 2011. ${ }^{16}$ Beertelsen et al found that the prevalence of Leber congenital amaurosis, Usher syndrome and Bardet-Biedl syndrome had doubled and that a possible explanation was a documented history of consanguinity in more than one third of children. ${ }^{16}$ Prevention/treatment strategies include genetic counselling and gene therapy. ${ }^{17}$

Cortical (better termed cerebral visual impairment because the pathology is often subcortical) visual impairment was the second most common single cause of certifiable severe sight impairment and the third most common single cause of certifiable sight impairment in children in England and Wales. Children with this problem often also have pale or small optic nerves which is why we have grouped optic nerve and visual pathway problems together. This is seen with increased frequency in low birth weight $(<2500 \mathrm{~g})$ and in pre term births, the rate of which has risen in the UK. ${ }^{18}$ Improved survival of extremely premature babies and children with multiple disabilities is also like to contribute to this increase and also to the increase in ROP blindness since it is these babies that are most in danger of both problems. ${ }^{19}$ Prevention of cerebral visual impairment will probably involve better neonatal neuroprotection. For instance improved neuro-cognitive outcomes have been demonstrated with brain cooling ${ }^{20}$ but visual outcomes have so far largely been neglected. Prevention of visual impairment due to ROP depends on robust screening programmes and outcomes may improve with new treatment modalities. ${ }^{21}$ Since the retina is part of the CNS, common treatments may emerge for cerebral visual impairment and ROP. ${ }^{22}$ 
A Causes of severe sight impairment in children

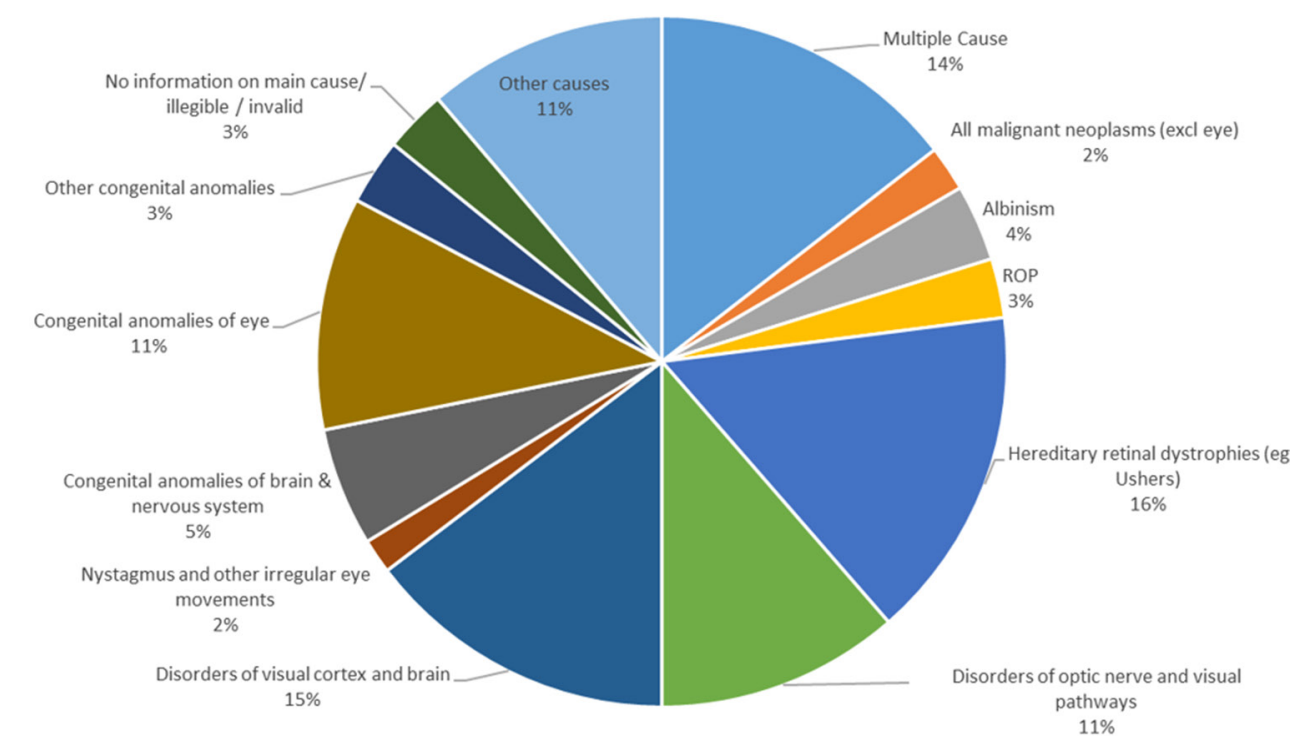

Figure 2 (A) Causes of severe sight impairment in children in England \& Wales, 2015/2015. (B) Causes of sight impairment in children in England \& Wales, 2015/2015.

Nystagmus was the second most common cause of certifiable SI in children. Some treatments have been shown to be beneficial in adults with congenital nystagmus ${ }^{23}$ and it may be that earlier intervention will have the chance to improve visual outcomes in the future.

One limitation of this study is that single main causes of certifiable sight impairment only are reported. Ocular conditions which occur commonly with other ocular conditions rendering it difficult to determine a single main cause will not feature as a common main cause yet still contribute to certifiable visual loss. Mitry et al examined causes of certification in children in England and Wales in 1999/2000, 2007/2008, 2008/2009 and 2009/2010 and investigated both single and multiple causes of certifiable sight impairment. ${ }^{11}$ Adjustment for multiple pathology did increase figures for cerebral visual impairment and nystagmus slightly more than figures for retinal dystrophies but Mitry concluded that analysis which includes multiple causes did not reveal major changes in proportions of causes than using a single main cause. ${ }^{11}$

We did not find evidence that the increase observed in certification rates over time was due to a change in the age of children being certified as evidenced by similar median ages of each yearly group.

Certification is the first step in registration which entitles families and children to support and assistance. We previously reported on an increase in registration figures for children (from 1982 to 2011). We believed that this 
had not been commented on widely because registration figures for adults had not shown this trend and children account for $<1 \%$ of all registrations. We advised caution with respect to inferring that these trends meant that childhood blindness had increased because the CVI is not a population based indicator and because we had not examined causal data. This study demonstrates that certification figures mirror registration figures and that the causes of sight impairment in those being certified are those which are likely to have increased over time. We believe therefore that there is evidence that the numbers of children with sight impairment has grown in the UK with implications for the provision of both preventive and support services.

Contributors $\mathrm{CB}$ and AZ drafted the paper and conducted the statistical analysis. $\mathrm{RB}$ and RW provided substantial contribution to the interpretation of the data. All authors revised the paper critically.

Funding This research received no specific grant from any funding agency in the public, commercial or not-for-profit sectors. CB is in part funded by the National Institute for Health Research(NIHR) Biomedical Research Centre based at Guy's and St Thomas' NHS FoundationTrust and King's College London.

Competing interests The data provided by Moorfields Eye Hospital, captured by the Certificate of Vision impairment (CVI) are Department of Health copyright and this work was made possible by collaboration with the Royal College of Ophthalmologists. Any views expressed in the publication are those of the author(s) alone and are not necessarily those of the Department of Health, the NHS or the NIHR.

Ethics approval This was an analysis of anonymised data. No ethical approval was required. Patients do however provide written informed consent to their data being sent to the Certifications Office, London and to their data being used for epidemiological analysis.

Provenance and peer review Not commissioned; externally peer reviewed.

Data sharing statement The data provided by Moorfields Eye Hospital, captured by the Certificate of Vision impairment (CVI) are Department of Health copyright and this work was made possible by collaboration with the Royal College of Ophthalmologists. Data are overseen by the Certificate of Vision Impairment Committee. Additional data may be obtained from the Certifications Office.

Open Access This is an Open Access article distributed in accordance with the Creative Commons Attribution Non Commercial (CC BY-NC 4.0) license, which permits others to distribute, remix, adapt, build upon this work non-commercially, and license their derivative works on different terms, provided the original work is properly cited and the use is non-commercial. See: http://creativecommons.org/ licenses/by-nc/4.0/

(C) Article author(s) (or their employer(s) unless otherwise stated in the text of the article) 2017. All rights reserved. No commercial use is permitted unless otherwise expressly granted.

\section{REFERENCES}

1. Gilbert C, Foster A. Childhood blindness in the context of VISION 2020--the right to sight. Bull World Health Organ 2001;79:227-32.
2. Rahi JS, Cable N; British Childhood Visual Impairment Study Group. Severe visual impairment and blindness in children in the UK. Lancet 2003;362:1359-65.

3. Bunce C, Evans J, Fraser S, et al. BD8 certification of visually impaired people. Br J Ophthalmol 1998;82:72-6.

4. Boyce T, Dahlmann-Noor A, Bowman R, et al. Support for infants and young people with sight loss: a qualitative study of sight impairment certification and referral to education and social care services. BMJ Open 2015;5:e009622.

5. Mitry D, Bunce C, Wormald R, et al. Childhood visual impairment in England: a rising trend. Arch Dis Child 2013;98:378-80.

6. Health and Social Care Information Centre. Registered Blind and partially Sighted People: year ending 31 March 2014: England Copyright @ 2014.

7. Rahi JS, Dezateux C. Epidemiology of visual impairment in Britain. Arch Dis Child 1998;78:381-6.

8. Bunce $C$, Wormald R. Leading causes of certification for blindness and partial sight in England \& Wales. BMC Public Health 2006;6:58.

9. Breslow NE, Day NE, World Health Organisation. Statistical methods in cancer research, volume II: the design and analysis of cohort studies: Lyon: International Agency for Research on Cancer,, 1987.

10. Pilling RF, Outhwaite L. Are all children with visual impairment known to the eye clinic? Br J Ophthalmol 2017;101:472-4.

11. Mitry D, Bunce C, Wormald R, et al. Causes of certifications for severe sight impairment (blind) and sight impairment (partial sight) in children in England and Wales. Br J Ophthalmol 2013;97:1431-6.

12. Hamblion EL, Moore AT, Rahi JS. British Childhood Onset hereditary retinal disorders Network incidence and patterns of detection and management of childhood-onset hereditary retinal disorders in the UK. Br J Ophthalmol 2012;96:360-5.

13. Sheridan E, Wright J, Small N, et al. Risk factors for congenital anomaly in a multiethnic birth cohort: an analysis of the born in Bradford study. The Lancet/ssue 2013;382:1350-9.

14. Jivraj S. How has the ethnic diversity grown 1991-2001-2011? the Dynamics of Diversity; evidence from the 2011 Census: ESPR Centre on Dynamics of Ethnicity (CoDE). http://www.ethnicity. ac.uk/research/outputs/briefings/dynamics-of-diversity/ doa 19/9/2016.

15. Kliner M, Fell G, Pilling RF, et al. Visual impairment in children. Eye 2011;25:1097.

16. Bertelsen $\mathrm{M}$, Jensen $\mathrm{H}$, Larsen $\mathrm{M}$, et al. Prevalence and diagnostic spectrum of generalized retinal dystrophy in danish children. Ophthalmic Epidemiol 2013;20:164-9.

17. Bainbridge JW, Mehat MS, Sundaram V, et al. Long-term effect of gene therapy on Leber's congenital amaurosis. N Engl J Med 2015;372:1887-97.

18. Moser K, Li L, Power C. Social inequalities in low birth weight in England and Wales: trends and implications for future population health. J Epidemiol Community Health 2003;57:687-91.

19. Costeloe KL, Hennessy EM, Haider S, et al. Short term outcomes after extreme preterm birth in England: comparison of two birth cohorts in 1995 and 2006 (the EPICure studies). BMJ 2012;345:e7976.

20. Azzopardi D, Strohm B, Marlow N, et al. TOBY Study Group. Effects of hypothermia for perinatal asphyxia on childhood outcomes. $N$ Engl $J$ Med 2014;371:140-9.

21. Sankar MJ, Sankar J, Mehta M, et al. Anti-vascular endothelial growth factor (VEGF) drugs for treatment of retinopathy of prematurity. Cochrane Database Syst Rev 2016;2. CD009734. doi.

22. Liegl R, Löfqvist C, Hellström A, et al. IGF-1 in retinopathy of prematurity, a CNS neurovascular disease. Early Hum Dev 2016;102:1330404-19.

23. McLean R, Proudlock F, Thomas S, et al. Congenital nystagmus: randomized, controlled, double-masked trial of memantine/ gabapentin. Ann Neurol 2007;61:130-8. 